\title{
Prevalence and Influencing Factors of Thyroid Dysfunction in HIV-Infected Patients
}

\author{
Shujing Ji, ${ }^{1,2}$ Changzhong Jin, ${ }^{1,2}$ Stefan Höxtermann, ${ }^{3}$ Wolfgang Fuchs, ${ }^{3}$ \\ Tiansheng Xie, ${ }^{1,2}$ Xiangyun Lu, ${ }^{1,2}$ Haibo Wu, ${ }^{1,2}$ Linfang Cheng, \\ Adriane Skaletz-Rorowski, ${ }^{3}$ Norbert $\mathrm{H}$. Brockmeyer, ${ }^{3}$ and Nanping $\mathrm{Wu}^{1,2}$ \\ ${ }^{1}$ State Key Laboratory for Diagnosis and Treatment of Infectious Diseases, The First Affiliated Hospital, \\ School of Medicine, Zhejiang University, Hangzhou 310003, China \\ ${ }^{2}$ Collaborative Innovation Center for Diagnosis and Treatment of Infectious Diseases, Hangzhou 310003, China \\ ${ }^{3}$ Department of Dermatology and Allergology, St. Josef-Hospital, Ruhr-University Bochum, 44791 Bochum, Germany
}

Correspondence should be addressed to Norbert H. Brockmeyer; n.brockmeyer@derma.de and Nanping Wu; flwnp2013@163.com Received 11 December 2015; Revised 8 March 2016; Accepted 4 April 2016

Academic Editor: Handan Wand

Copyright (C) 2016 Shujing Ji et al. This is an open access article distributed under the Creative Commons Attribution License, which permits unrestricted use, distribution, and reproduction in any medium, provided the original work is properly cited.

Thyroid dysfunction is more common in human immunodeficiency virus (HIV) patients. But the effects of highly active antiretroviral therapy (HAART) and hepatitis $\mathrm{B} / \mathrm{C}$ virus $(\mathrm{HBV} / \mathrm{HCV})$ coinfection on thyroid function is unclear. We retrospectively reviewed the data of $178 \mathrm{HIV}$ patients and determined the prevalence of thyroid dysfunction and the relationship between thyroid hormone levels, CD4 cell count, HIV-1 duration, HAART duration/regimens, and HBV/HCV coinfection. Of the 178 patients, 59 (33.1\%) had thyroid dysfunction, mostly hypothyroidism. Thyroid dysfunction was significantly more frequent in the HAART group $(41 / 104,39.4 \%)$ than in the HAART-naive group $(18 / 74,24.3 \% ; P<0.05)$. The mean CD4 cell count was significantly lower in patients with hypothyroidism $(372 \pm 331 / \mu \mathrm{L})$ than in the other patients $(P<0.05)$. The FT4 level was significantly lower in the HAART group than in the HAART-naive group $(1.09 \pm 0.23$ versus $1.20 \pm 0.29 \mathrm{pg} / \mathrm{mL}, P<0.05)$. FT3/FT4 levels were negatively related to HIV duration and FT3 levels were positively related to CD4 cell $(P<0.05)$. HBV patients had lower FT3 levels, while HCV patients had higher FT3 and FT4 levels $(P<0.05)$. Thyroid dysfunction is more common in HIV patients on HAART, mainly manifested as hypothyroidism. FT3/FT4 levels are correlated with HIV progression. HBV/HCV coinfection increases the probability of thyroid dysfunction.

\section{Introduction}

Human immunodeficiency virus (HIV) infection is characterized by decreased CD4 cell count and immunodeficiency, leading to opportunistic infections (OIs) and tumors [1]. In recent years, increasing number of patients with HIV infection are able to survive for long periods because of the extensive application of highly active antiretroviral therapy (HAART) for the repression of viral replication as well as because of the emergence of new medicines and therapeutic regimens. Many nonacquired immune deficiency syndrome(AIDS-) related diseases now primarily account for the disease burden in patients with HIV infection. Abnormalities of the endocrine function of the pituitary, thyroid, adrenals, gonads, and pancreas and in metabolism are common in patients infected with HIV and are becoming the main conditions influencing the long-term quality of life in HIVinfected patients [2-8]. Some studies have reported complications such as hypertriglyceridemia and hypercholesterolemia, lipodystrophy and lipoatrophy, glucose intolerance and type 2 diabetes mellitus, gonadal dysfunction, and osteopenia and osteoporosis during HAART [2, 9-13]. Thyroid hormone, an important hormone regulating metabolism, can also be affected by HIV infection. Numerous studies have reported that the incidence of thyroid dysfunction is much higher (about 36\%-37\%) in patients infected with HIV than in the general population $[14,15]$. However, other researchers have suggested that the morbidity of overt thyroid dysfunction in 
patients infected with HIV is similar to that in the general population [2-8, 15-21]. Therefore, further research into the prevalence of thyroid dysfunction in patients infected with $\mathrm{HIV}$ is required.

Thyroid dysfunction reduces the quality of life of patients infected with HIV. Overt hypothyroidism leads to the insidious onset of fatigue, weakness, dry skin, cold intolerance, slowed mentation, constipation, hoarse voice, paresthesia, bradycardia, and delayed relaxation of tendon reflexes. Overt hyperthyroidism is characterized by irritability, heat intolerance, sweating, warm moist skin, palpitations, tachycardia, fatigue, weight loss with increased appetite, diarrhea, tremor, muscle weakness, hyperreflexia, and lid retraction. The consequences of subclinical hyperthyroidism include reduced bone mineral density and an increased risk of atrial fibrillation, the risk of which is proportional to the degree of thyroid hyperfunction [15]. Furthermore, subclinical hyperthyroidism may precede overt hyperthyroidism $[20,22]$. It is unclear why HIV-infected patients are susceptible to thyroid dysfunction, but HIV infection is regarded as a crucial factor. Furthermore, the influence of HIV infection on thyroid function changes with the course of the disease. Asymptomatic, subtle abnormalities of thyroid function tests have been described in a small minority of patients with stable HIV infection $[2,16,17]$. With the progression of the disease, a pattern of sick euthyroid syndrome may develop. The most frequent abnormalities in thyroid function tests are those associated with subclinical hypothyroidism [2, 15, 22-24]. The medications used to treat HIV infection are also a vital factor leading to abnormalities in thyroid function. Some reports have indicated that HAART increases the probability of thyroid dysfunction. Stavudine has been suggested to directly affect the production and/or metabolism of thyroid hormones $[2,14,22,24]$. Prolonged treatment with stavudine contributes to a decrease in free thyroxine (FT4) level [2]. Bongiovanni et al. showed that the accumulation of the daily intake of stavudine and lamivudine is responsible for the occurrence of hypothyroidism [1]. Beltran et al. found that stavudine and low CD4 cell counts were associated with hypothyroidism [22]. Parsa and Bhangoo determined that stavudine was most often associated with subclinical hypothyroidism [20, 25-27]. Madeddu et al. reported that thyroid-stimulating hormone (TSH) was negatively correlated with CD4 cell count nadir and positively correlated with HAART duration [2]. They also reported that there was no significant correlation between free tri-iodothyronine (FT3), FT4, age, duration of HIV infection, duration of HAART, CD4 cell count, and CD4 cell count nadir [2]. Besides HAART, treatment regimens including rifampicin or immunomodulatory agents have often been reported to alter thyroid hormone levels with clinical effects in patients with HIV-related diseases [2, 28, 29]. Furthermore, some researchers have suggested that hepatitis $B$ virus (HBV) and/or hepatitis $\mathrm{C}$ virus (HCV) coinfection increases the risk of thyroid dysfunction in HIV-infected patients, and according to Beltran et al., HCV coinfection is a risk factor for hypothyroidism [22]. Thus far, the relationship between thyroid dysfunction and HIV infection is obscure, especially, with respect to the state of HIV and HAART.
In addition, the influence of drugs other than stavudine on thyroid function, such as protease inhibitors (PIs), integrase inhibitors (IIs), and CCR5 antagonists, has not yet been reported. In this study, we analyzed the thyroid function of 178 patients infected with HIV, of which 104 were on HAART. We found that thyroid dysfunction was common in patients infected with HIV, especially, in patients on HAART, and hypothyroidism accounted for the majority of cases of thyroid dysfunction. Moreover, the levels of FT3 and FT4 were related to disease progression. PIs and IIs had no significant influence on thyroid function, and hyperthyroidism frequently occurred in patients with HCV coinfection.

\section{Materials and Methods}

2.1. Subjects. We analyzed the clinical information of 178 HIV patients who were treated at St. Josef-Hospital, RuhrUniversity Bochum, between June and September 2014. In all patients, HIV infection was diagnosed by the detection of HIV antibodies in blood using enzyme-linked immunosorbent assay (ELISA) and western immunoblot analysis. Disease stages of HIV-1 patients were diagnosed based on CDC revised classification system for HIV infection and expanded surveillance case definition for AIDS among adolescents and adults (1993) [30]. Of the 178 patients, 104 were treated with HAART, while 74 were HAART-naïve. We recorded the age, sex, transmission route and duration of HIV infection, and the duration and type of therapeutic regimens used. The course of the disease was defined as the duration of HIV infection calculated from the first HIV-positive test result [22], and the course of HAART was calculated from the day on which HAART was started. Patients were systematically screened for coinfection with HCV or HBV.

2.2. Laboratory Tests. CD4 cell count was measured by flow cytometry (FACSCantoII, Becton Dickinson, Franklin Lakes, NJ, USA), and plasma HIV load (HIV RNA) was determined using a standardized reverse transcriptase-polymerase chain reaction assay (Cobas Amplicor HIV-1 Monitor Test, version 1.5, Ultrasensitive specimen preparation, Roche Diagnostic Systems Inc., Branchburg, NJ, USA). The lower limit of detection in plasma was $50 \mathrm{HIV}-1$ RNA copies/mL. HCV infection was detected by measuring antibodies to HCV in serum samples by using ELISA (Ortho HCV 3.0 ELISA test, Ortho Clinical Diagnostic, Amersham, Buckinghamshire, UK) and an immunoblot assay (SIA, Chiron RIBA, Chiron Corporation, Emeryville, CA, USA). HBV infection was detected by measuring the hepatitis B surface antigen level using an enzymelinked fluorescent assay (Biomerieux, Lyon, France). Serum TSH level was measured by a one-step radioimmunometric assay (IRMA-mat, Byk-Sangtec Diagnostica, Dietzenbach, Germany), and serum FT3 and FT4 levels were measured using radioimmunological assays (Amerlex MAB, Ortho Clinical Diagnostics, Milan, Italy).

2.3. Definition of Thyroid Function Abnormalities. The normal ranges of TSH, FT3, and FT4 were $0.27-4.20 \mu \mathrm{IU} / \mathrm{mL}$, $2.00-4.40 \mathrm{pg} / \mathrm{mL}$, and $0.93-1.70 \mathrm{pg} / \mathrm{mL}$, respectively. Overt hypothyroidism was defined as a low FT3 and/or FT4 level, 
TABLE 1: Demographic and clinical characteristics of 178 HIV patients.

\begin{tabular}{|c|c|c|c|c|}
\hline Parameter & HAART & Naïve & Total & $P$ value \\
\hline Number & $104(58.4 \%)$ & $74(41.6 \%)$ & 178 & \\
\hline Age (years) & $50.18 \pm 10.19$ & $46.68 \pm 11.64$ & $48.72 \pm 10.92$ & 0.34 \\
\hline Sex & & & & 0.829 \\
\hline Males $(n)$ & $90(86.5 \%)$ & $63(85.1 \%)$ & 153 & \\
\hline Females $(n)$ & $14(13.5 \%)$ & $11(14.9 \%)$ & 25 & \\
\hline HIV transmission category & & & & 0.368 \\
\hline Blood & $1(1.0 \%)$ & $1(1.4 \%)$ & 2 & \\
\hline IVDU & $2(1.9 \%)$ & $1(1.4 \%)$ & 3 & \\
\hline MSM & $69(66.3 \%)$ & $47(63.5 \%)$ & 116 & \\
\hline Sexual transmitted & $16(15.4 \%)$ & $18(24.3 \%)$ & 34 & \\
\hline Unknown & $16(15.4 \%)$ & $7(9.5 \%)$ & 23 & \\
\hline CDC stage & & & & $<0.001$ \\
\hline $\mathrm{A}$ & $57(54.8 \%)$ & $19(25.7 \%)$ & $76(42.7 \%)$ & \\
\hline $\mathrm{B}$ & $37(35.6 \%)$ & $31(41.9 \%)$ & $68(38.2 \%)$ & \\
\hline $\mathrm{C}$ & $10(9.6 \%)$ & $24(32.4 \%)$ & $34(19.1 \%)$ & \\
\hline $\log \mathrm{VL}$ & $1.06 \pm 1.64$ & $4.12 \pm 1.82$ & $2.33 \pm 2.29$ & $<0.001$ \\
\hline $\mathrm{CD} 4$ & $547 \pm 305$ & $392 \pm 319$ & $483 \pm 319$ & 0.001 \\
\hline CD4 nadir & $371 \pm 225$ & $293 \pm 220$ & $339 \pm 226$ & 0.499 \\
\hline HIV infection duration (years) & $14.81 \pm 7.21$ & $7.81 \pm 5.26$ & $11.90 \pm 7.33$ & $<0.001$ \\
\hline Thyroid function & & & & 0.037 \\
\hline Normal & $63(60.6 \%)$ & $56(75.7 \%)$ & $119(66.9 \%)$ & \\
\hline Abnormal & $41(39.4 \%)$ & $18(24.3 \%)$ & $59(33.1 \%)$ & \\
\hline Subhypothyroidism & $9(8.7 \%)$ & $3(4.1 \%)$ & $12(6.6 \%)$ & \\
\hline Overt hypothyroidism & $28(26.9 \%)$ & $12(16.2 \%)$ & $40(22.1 \%)$ & \\
\hline Overt hyperthyroidism & $4(3.8 \%)$ & $3(4.1 \%)$ & $7(3.9 \%)$ & \\
\hline
\end{tabular}

HAART, HIV patients receiving highly active antiretroviral therapy (HAART); naïve: HAART naïve HIV patients; IVDU, intravenous drug user; MSM, men who have sex with men; VL: viral load.

with/without a high TSH level. Overt hyperthyroidism was defined as a high FT3 and/or FT4 level, with/without a low TSH level. Subclinical hypothyroidism was defined as a high TSH level with normal FT3 and FT4 levels, while subclinical hyperthyroidism was defined as a low TSH level with normal FT3 and FT4 levels. All the clinical and laboratory data was analyzed for patients with thyroid function abnormalities when they were first diagnosed with thyroid dysfunction in this cross-sectional study.

2.4. Statistical Analysis. Statistical analysis was performed using the SPSS (version 20; IBM Corp., Armonk, NY, USA). Numerical/continuous variables were reported as mean \pm standard deviation, and qualitative/categorical variables were expressed as the number of cases and percentages. Group means were compared using the independent-samples $t$-test, $F$-test, and $\chi^{2}$ test. The Pearson correlation coefficient was used to assess the association between numerical/continuous variables and Spearman correlation coefficient was used to assess the association between discrete variables. All comparisons were two-sided, and $P<0.05$ was the cutoff value for statistical significance. Univariate and multivariate logistic regression analyses were done, and probability for stepwise was 0.1 to entry and 0.15 to removal.

\section{Results}

3.1. Clinical Information of HIV-Infected Patients. The mean age of the $104 \mathrm{HIV}$-infected patients treated with HAART was $50.18 \pm 10.19$ years, and the mean duration of HAART was $7.42 \pm 5.2$ years. The mean age of the 74 HAART-naïve patients was $46.68 \pm 11.64$ years. There were multiple routes of transmission, and $69(66.3 \%)$ patients on HAART and 47 (63.5\%) HAART-naïve patients were infected via homosexual acts. The duration of HIV infection was significantly longer in the HAART patients $(14.81 \pm 7.21$ years $)$ than in the HAART-naïve patients $(7.81 \pm 5.26$ years; $P<0.05)$. The viral load was significantly lower in the HAART group [10E $(1.06 \pm 1.64)]$ than in the HAART-naïve group [10E $(4.12 \pm$ $1.82)](P<0.05)$. CD4 cell count was higher in the HAART group $(547 \pm 305 / \mu \mathrm{L})$ than in the HAART-naïve group $(392 \pm$ $319 / \mu \mathrm{L} ; P<0.05$; Table 1$)$. CD4 cell count nadirs were not significantly different between HAART and HAART-naïve groups $(370.96 \pm 225.25$ versus $293.26 \pm 220.45 / \mu \mathrm{L}, P=0.499$, Table 1). There were many more patients diagnosed with CDC class 1 in the HAART group than in HAART-naïve group (57 $(54.8 \%)$ versus $19(26.0 \%))(P<0.05$; Table 1$)$. There were totally $34(19.1 \%)$ patients diagnosed with OIs, of whom 22 were diagnosed with herpes infection and 7 were diagnosed with thrush. 
3.2. Prevalence of Thyroid Dysfunction in HIV-1-Infected Patients. Of the 178 study patients, 59 (33.1\%) were diagnosed with thyroid dysfunction, including 12 (6.6\%) patients with subclinical hypothyroidism, 40 (22.1\%) with overt hypothyroidism, and 7 (3.9\%) patients with overt hyperthyroidism. There were not any patients with subclinical hyperthyroidism. 41 of the patients with overt thyroid dysfunction had normal TSH levels, including 34 with overt hypothyroidism and 7 with overt hyperthyroidism. Thyroid dysfunction was significantly more frequent in patients on HAART than in HAART-naive patients $(P<0.05)$. Of the 104 patients on HAART, $41(39.4 \%)$ had thyroid dysfunction, including 9 (8.7\%) with subclinical hypothyroidism, 28 (26.9\%) with overt hypothyroidism, and 4 (3.8\%) with overt hyperthyroidism. Of the 74 HAART-naive patients, 18 (24.3\%) patients had thyroid dysfunction, including 3 (4.1\%) with subclinical hypothyroidism, 12 (16.2\%) with overt hypothyroidism, and 3 (4.1\%) with overt hyperthyroidism. Hypothyroidism was the most frequent dysfunction. Thyroid dysfunction was significantly more frequent in the HAART group than in the HAART-naïve group $(P=0.006$, Table 1$)$. The mean thyroid hormone (TSH, FT3, and FT4) levels in patients with thyroid dysfunction and those with normal thyroid function are shown in Figure 1. The mean CD4 cell count was significantly lower in patients with overt hypothyroidism $(372 \pm 331 / \mu \mathrm{L})$ than in patients in the other groups shown in Figure $1(P<$ $0.05)$. But the counts of CD4 cell nadir were similar among the four groups of patients.

We found no different incidence of thyroid dysfunction in patients of different CDC classes. FT3 level was higher in patients of CDC class $1(3.32 \pm 0.67 \mathrm{pg} / \mathrm{mL})$ than in patients of CDC class $3(2.55 \pm 0.86 \mathrm{pg} / \mathrm{mL}, P<0.05)$. Neither TSH nor FT4 levels were different among patients of the three CDC classes. We also compared the incidence of thyroid dysfunction between patients with and without OIs. No different incidence of thyroid dysfunction and different levels of thyroid hormones were found in patients with OIs compared with those without OIs.

3.3. Effect of HAART on Thyroid Hormone Levels. The FT3 and FT4 levels in the HAART group were $3.09 \pm 0.73 \mathrm{pg} / \mathrm{mL}$ and $1.09 \pm 0.23 \mathrm{pg} / \mathrm{mL}$, respectively. Both these values were lower than the levels in the HAART-naive patients $(3.12 \pm$ $0.86 \mathrm{pg} / \mathrm{mL}$ and $1.20 \pm 0.29 \mathrm{pg} / \mathrm{mL}$, resp.); however, only the difference between the FT4 levels was significant $(P<0.05)$. The TSH level was higher in the HAART group $(2.09 \pm$ $2.53 \mu \mathrm{IU} / \mathrm{mL})$ than in the HAART-naive group $(1.87 \pm$ $1.37 \mu \mathrm{IU} / \mathrm{mL}, P=0.446$; Figure 2).

We also found that the levels of FT3 and FT4 were negatively correlated with the duration of HIV infection and positively correlated with CD4 cell count in the HAART and HAART-naïve groups $(P<0.05)$, although the strength of the correlation was weak (Table 2). The FT3 and FT4 levels were not significantly related to HAART duration, viral load, CD4 cell count nadir, or any other parameters. No relevance was found between TSH levels or any of the above disease parameters.

We further studied the effect of different HAART regimens on thyroid function. As none of patients were taking
TABLE 2: Correlation between thyroid hormone levels and HIV infection.

\begin{tabular}{lcc}
\hline & $R$ value & $P$ value \\
\hline FT3 and HIV duration & -0.221 & 0.004 \\
FT4 and HIV duration & -0.213 & 0.006 \\
CD4 and FT3 & 0.230 & 0.003 \\
\hline
\end{tabular}

stavudine, we divided the 104 patients with HAART into four subgroups: 28 (26.9\%) patients taking two nucleoside reverse transcriptase inhibitors (NRTIs) + PI; 40 (38.5\%) patients taking two NRTIs + nonnucleoside reverse transcriptase inhibitors (NNRTIs); 21 (20.2\%) patients taking two NRTIs + II; and 15 (14.4\%) patients following other therapeutic regimens. Thyroid hormone levels did not differ among these four subgroups, indicating that there were no significant differences in the effects of PIs, IIs, and NNRTIs on thyroid function (Figure 3).

3.4. Effect of $H B V / H C V$ Coinfection on Thyroid Function. $\mathrm{HBV} / \mathrm{HCV}$ coinfection has been reported to lead to thyroid dysfunction, especially hypothyroidism [22]. We therefore divided the patients into three groups depending on the infectious agent: no coinfection (139 patients), HBV coinfection (31 patients), and HCV coinfection (8 patients). There were 43 (30.9\%) patients diagnosed with thyroid dysfunction in patients without coinfection, 14 (45.2\%) patients diagnosed with thyroid dysfunction in patients coinfected with $\mathrm{HBV}$, and $2(25 \%)$ patients diagnosed with thyroid dysfunction in patients coinfected with HCV. The FT3 and FT4 levels were significantly higher in the HCV patients $(3.60 \pm 0.64 \mathrm{pg} / \mathrm{mL}$, $1.31 \pm 0.15 \mathrm{pg} / \mathrm{mL}$, resp.) than the $\mathrm{HBV}$ patients $(2.82 \pm$ $0.85 \mathrm{pg} / \mathrm{mL}, 1.06 \pm 0.18 \mathrm{pg} / \mathrm{mL}$, resp., $P<0.05)$. The FT3 level was higher in patients without coinfection $(3.13 \pm 0.76 \mathrm{pg} / \mathrm{mL})$ than in those with HBV coinfection $(2.82 \pm 0.85 \mathrm{pg} / \mathrm{mL}, P<$ 0.05). No differences in TSH levels were found among these three groups of patients (Figure 4).

\subsection{Univariate and Multivariate Logistic Regression Fitted for} Thyroid Dysfunction. To control for possible confounding variables, we conducted univariate and multivariate logistic regression analysis. Univariate logistic regression revealed that sex was the only risk factor for thyroid dysfunction and the odds ratio (OR) and 95\% confidence interval (CI) were $2.082(0.884,4.903)(P=0.093)$ (Table 3). Females were at higher risk to suffer from thyroid dysfunction. Although duration of HIV infection and CD4 cell count nadir were related to thyroid dysfunction and their ORs and 95\% CIs were $1.047(1.003,1.093)(P=0.037)$ and $0.999(0.997,1.000)$ $(P=0.061)$ (Table 3$)$, they were not risk factors for thyroid dysfunction. Multivariate logistic regression indicated that ORs and 95\% CIs of sex, duration of HIV infection, and CD4 nadir were $2.231(0.919,5.414)(P=0.076), 1.057(1.011,1.105)$ $(P=0.014)$, and $0.998(0.997,1.000)(P=0.041)$, which were consistent with univariate logistic regression analysis. Transmission routes, HBV or HCV coinfection, viral load, CD4 cell count, and CDC classification had no significant relation to thyroid dysfunction. 


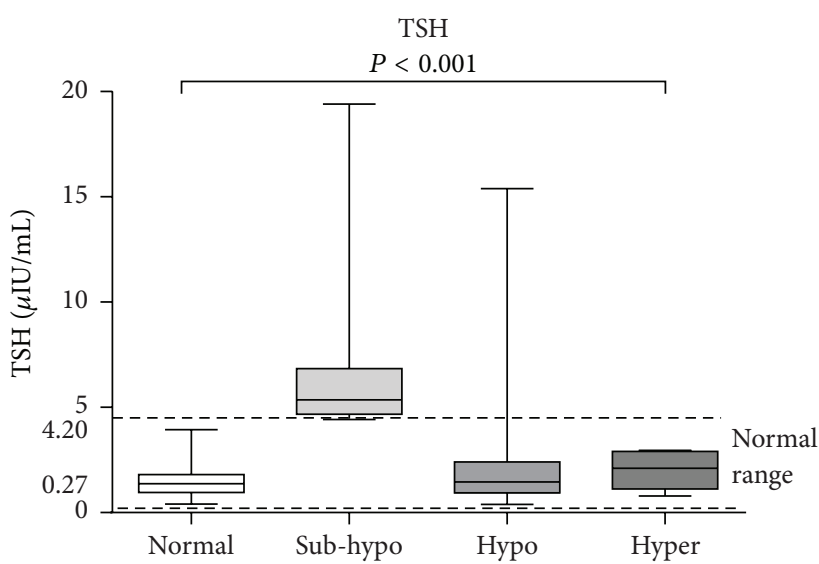

(a)

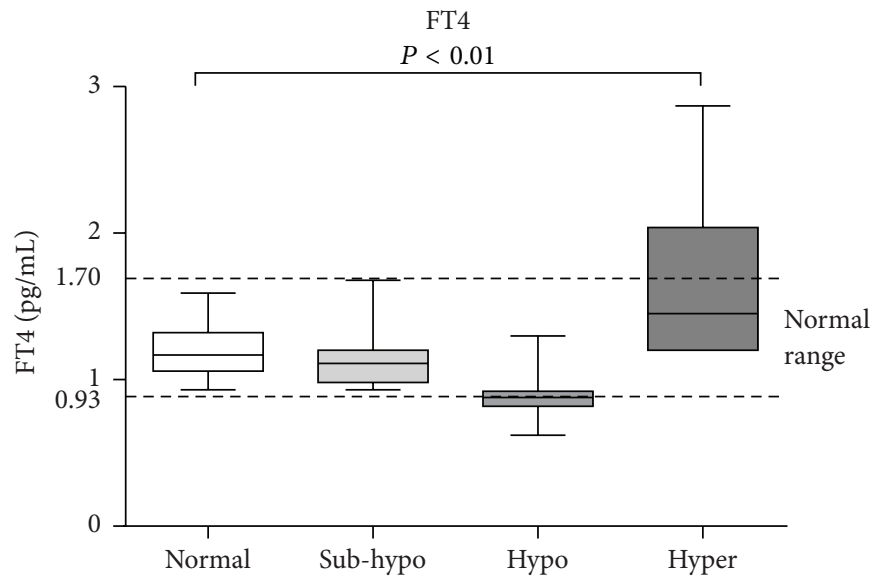

(c)

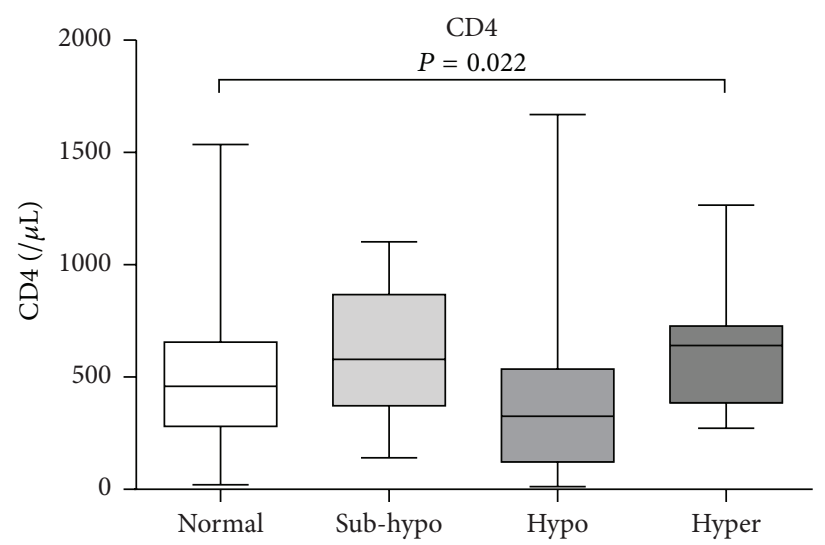

(e)

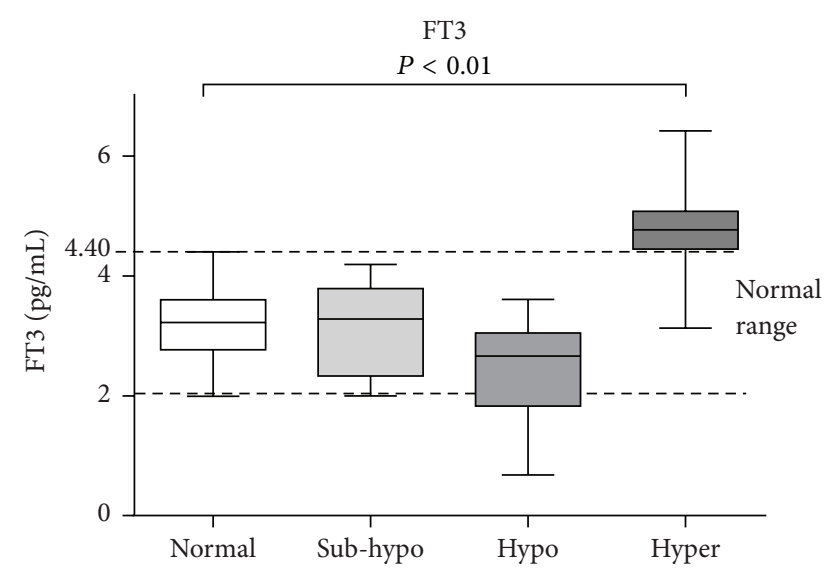

(b)

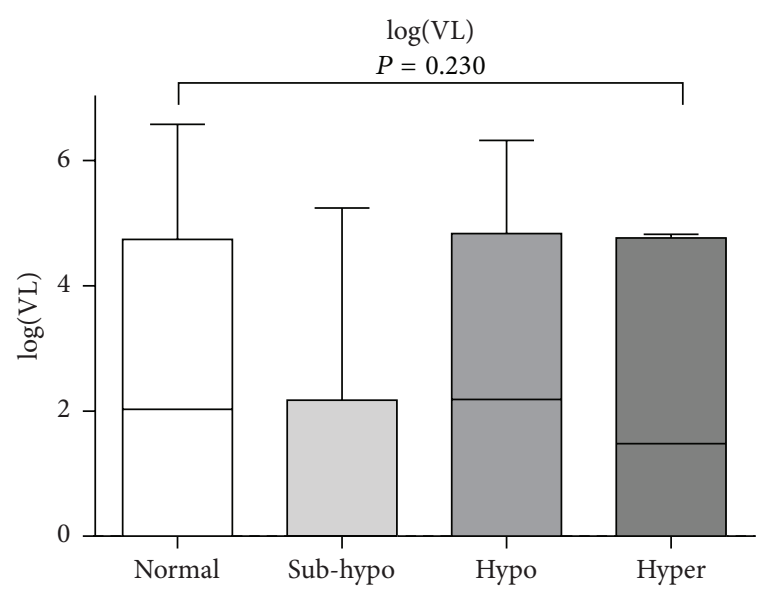

(d)

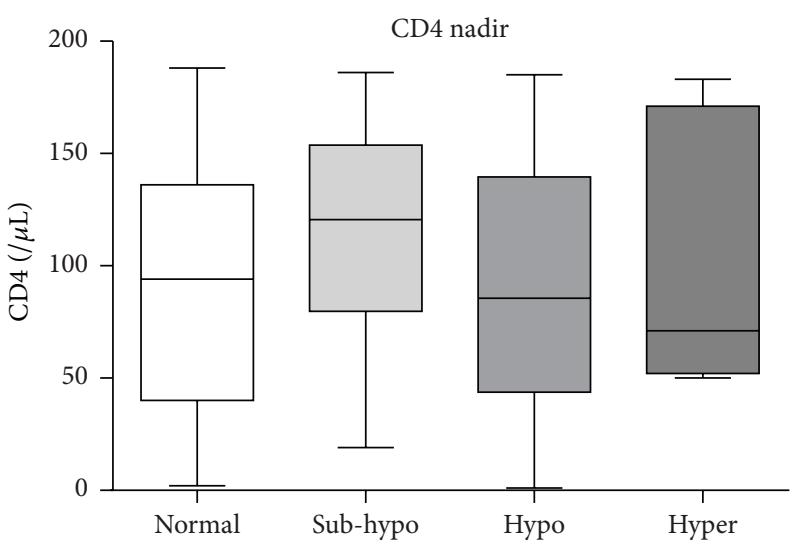

(f)

FIgURE 1: Thyroid hormone levels, HIV loads, and CD4 cell counts in patients with different thyroid function. FT3, free tri-iodothyronine; FT4, free thyroxine; TSH, thyrotropin; VL: viral load. Normal: normal thyroid function; sub-hypo: subclinical hypothyroidism; hypo: overt hypothyroidism; hyper: overt hyperthyroidism. The horizontal lines represent mean values, the boxes represent standard deviations, and the whiskers represent ranges. The dashed lines represent the normal ranges of thyroid hormones. The $P$ values in the figure were acquired using $\chi^{2}$ tests of the whole sample and not from comparisons between any two means.

\section{Discussion}

In our study, 33.1\% of HIV-infected patients were diagnosed with thyroid dysfunction, which is significantly higher than the rate reported by Beltran et al. (16\%) [22]. This difference may be attributable to the longer duration of HIV infection in our study, considering that FT3 and FT4 levels were negatively correlated with duration of HIV infection. The mean 
TABLE 3: Univariate and multivariate logistic regression models.

\begin{tabular}{|c|c|c|c|c|}
\hline & \multirow{2}{*}{ Odds ratio } & \multicolumn{2}{|c|}{$95 \% \mathrm{CI}$} & \multirow{2}{*}{$P$ value } \\
\hline & & Lower & Upper & \\
\hline \multicolumn{5}{|c|}{ Univariate logistic regression } \\
\hline Sex & 2.082 & 0.884 & 4.903 & 0.093 \\
\hline HIV infection duration & 1.047 & 1.003 & 1.093 & 0.037 \\
\hline CD4 nadir & 0.999 & 0.997 & 1.000 & 0.061 \\
\hline \multicolumn{5}{|c|}{ Multivariate logistic regression } \\
\hline Sex & 2.231 & 0.919 & 5.414 & 0.076 \\
\hline HIV infection duration & 1.057 & 1.011 & 1.105 & 0.014 \\
\hline CD4 nadir & 0.998 & 0.997 & 1.000 & 0.041 \\
\hline
\end{tabular}

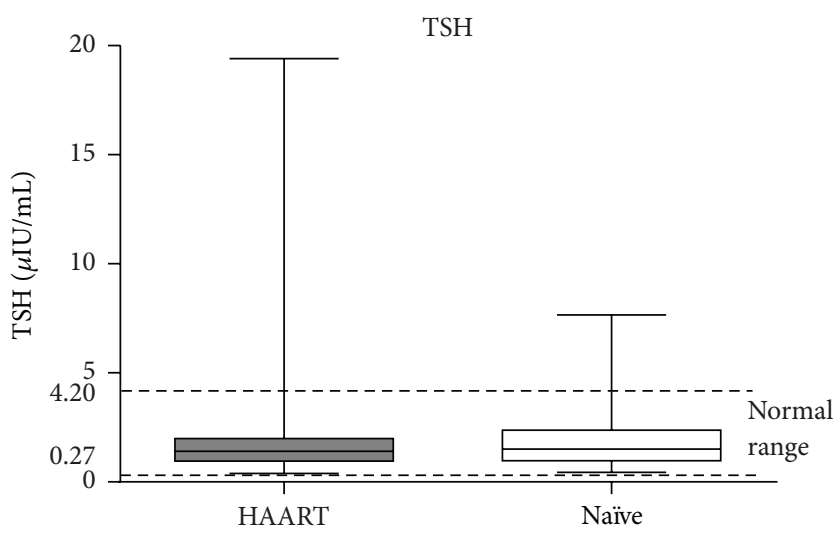

(a)

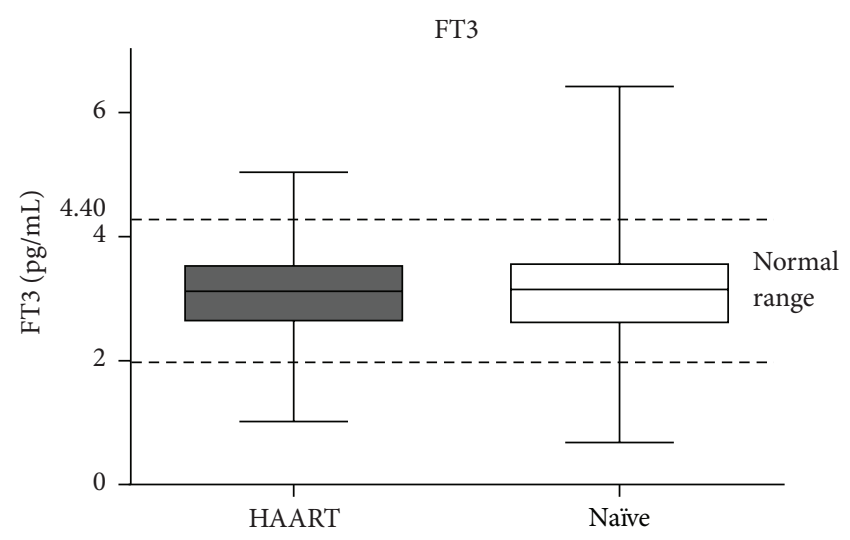

(b)

FT4

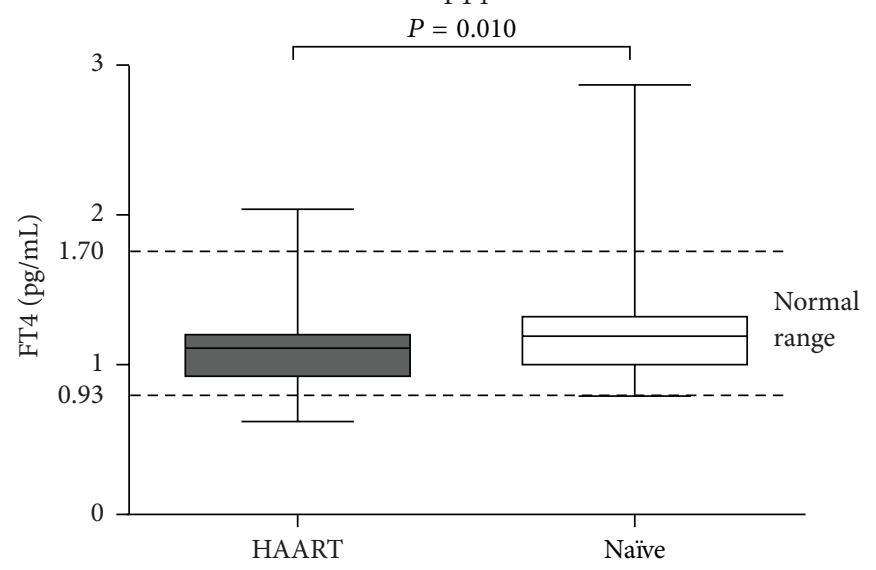

(c)

FIGURE 2: Thyroid hormone levels in patients on HAART and in HAART-naïve patients. FT3, free tri-iodothyronine; FT4, free thyroxine; TSH, thyrotropin; HAART, HIV patients receiving highly active antiretroviral therapy (HAART); Naïve: HIV patients who were HAARTnaive. The horizontal lines represent mean values, the boxes represent standard deviations, and the whiskers represent ranges. The dashed lines represent the normal ranges of thyroid hormones. $P$ values $>0.05$ in pairwise comparisons are not shown in the figure.

duration of HIV infection in the HAART and HAART-naive groups was $14.81 \pm 7.21$ years and $7.81 \pm 5.26$ years, respectively. Patients with longer HIV duration had lower FT3 and FT4 levels, indicating a higher possibility of hypothyroidism. Thyroid dysfunction was more common in the HAART group than in the HAART-naïve group, and clinical hypothyroidism was the most common thyroid dysfunction in
HIV-infected patients, which is consistent with the findings of Beltran et al. [22]. However, Madeddu et al. reported that subclinical hypothyroidism was the most frequent thyroid dysfunction in HIV patients treated with HAART [2, 22-24, 31]. While Hoffmann et al. concluded that the probability of clinical hypothyroidism in HIV-infected patients was similar to that in the general population, the probability of abnormal 


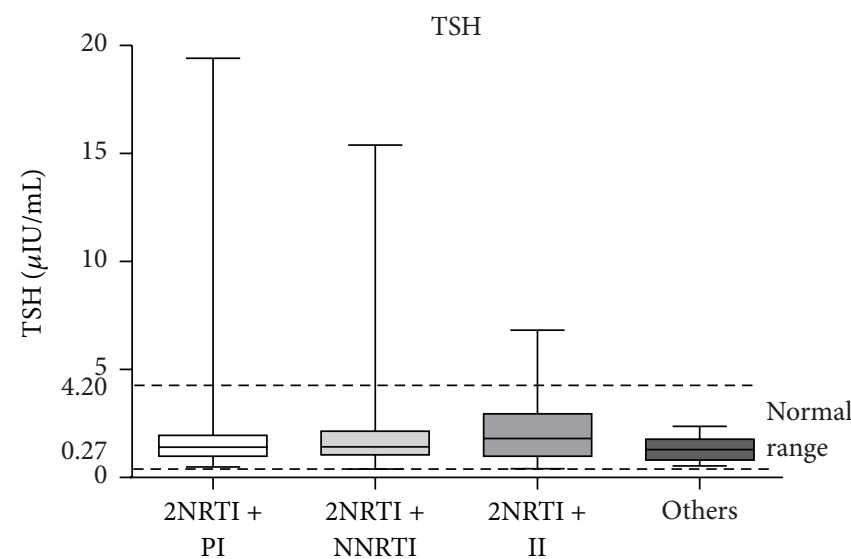

(a)

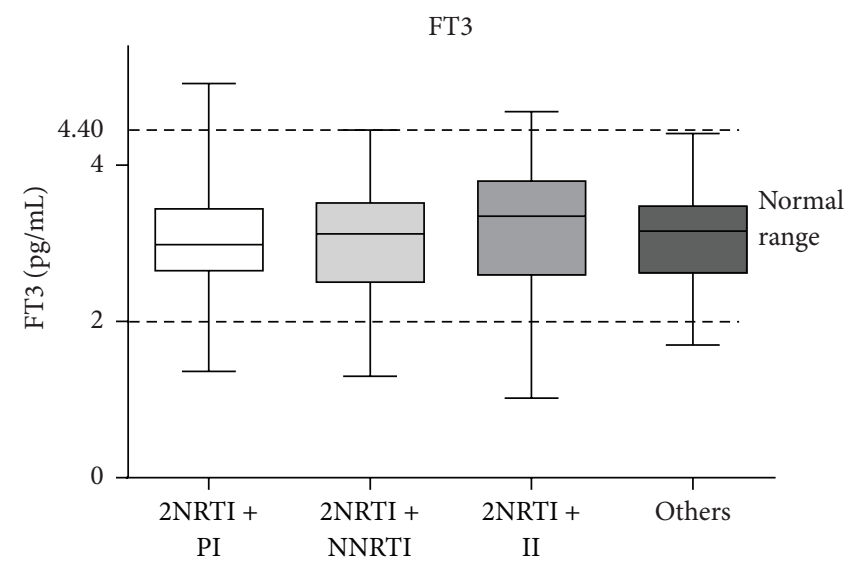

(b)

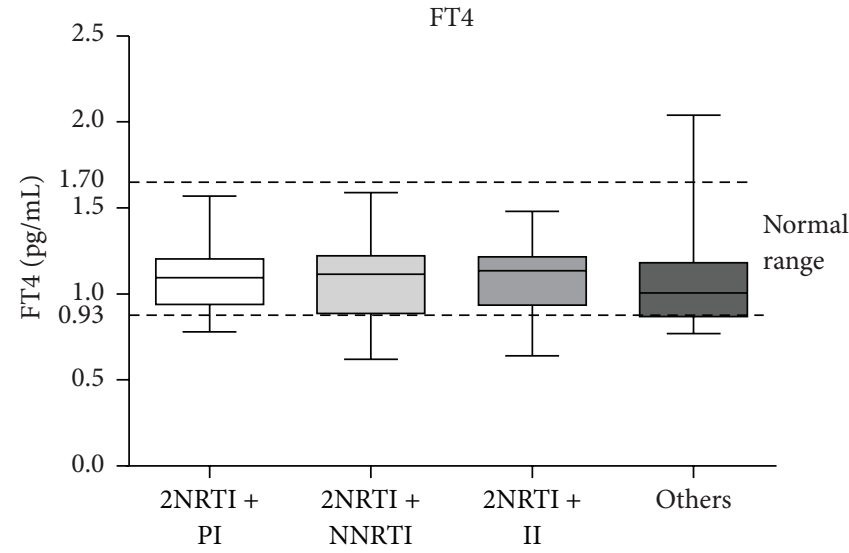

(c)

FIGURE 3: Thyroid hormone levels in HIV-infected patients on different therapies. FT3, free tri-iodothyronine; FT4, free thyroxine; TSH, thyrotropin; NRTI, nucleoside reverse transcriptase inhibitor; PI, protease inhibitor; NNRTI, nonnucleoside reverse transcriptase inhibitor; II: integrase inhibitor; others: other therapies (PI + II, 3 PIs, etc.). The horizontal lines represent mean values, the boxes represent standard deviations, and the whiskers represent ranges. The dashed lines represent normal ranges of thyroid hormones. $P$ values $>0.05$ in pairwise comparisons are not shown in the figure.

thyroid hormone test results was higher in the former group [1-3, 15-21]. Many patients are diagnosed with subclinical hypothyroidism during antiretroviral therapy $[2,15,22-24$, 31]. Graves' disease has often been reported during immune reconstitution [15]. The above differences in the incidence of thyroid dysfunction in HIV-infected patients may be related to differences in disease course, criteria of hypothyroidism, subclinical hypothyroidism, and so forth.

As far as we know, many cases of thyroid dysfunction in HIV-infected patients are attributable to HAART. Many longitudinal studies have demonstrated that HAART plays an important role in thyroid function abnormality appearance. A cohort study by Nelson et al. demonstrated that hypothyroidism was most commonly associated with PI and hyperthyroidism with NNRTI, especially efavirenz [32]. HAART could dramatically affect plasma HIV RNA and increased memory and naive CD4 cell; in the meantime, infectious or self-antigens might be produced and immune reconstitution inflammatory syndrome (IRIS) occurred to act against the antigens [33]. IRIS might lead to autoimmunity in HIV-1positive patients [34] and the majority of the hypothyroidism was regarded as a result of autoimmune etiology [35]. We therefore analyzed the effects of HAART on thyroid function and found that the FT4 level was significantly lower in the HAART group than in the HAART-naïve group. However, no significant differences in thyroid hormone levels were found among patients on different HAART regimens, indicating that there were no significant differences in the effects of PIs, IIs, and NNRTIs on TSH, FT3, and FT4 levels. A predominant and definite action by a single pharmaceutical product included in the HAART regimen that could affect thyroid function has not been consistently ascertained. Stavudine has been suggested to directly affect the production and/or metabolism of thyroid hormones [2, 14, 22, 24, 27]. A followup experiment by Madeddu et al. illustrated that prolonged stavudine treatment significantly decreased FT4 levels [2]. While Beltran et al. found on multivariate analysis that stavudine treatment and low CD4 cell counts were associated with 
TSH

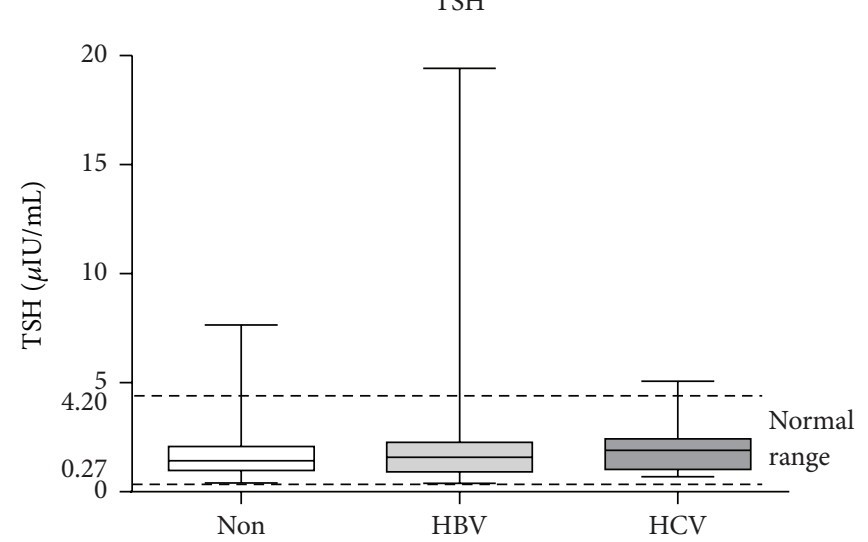

(a)

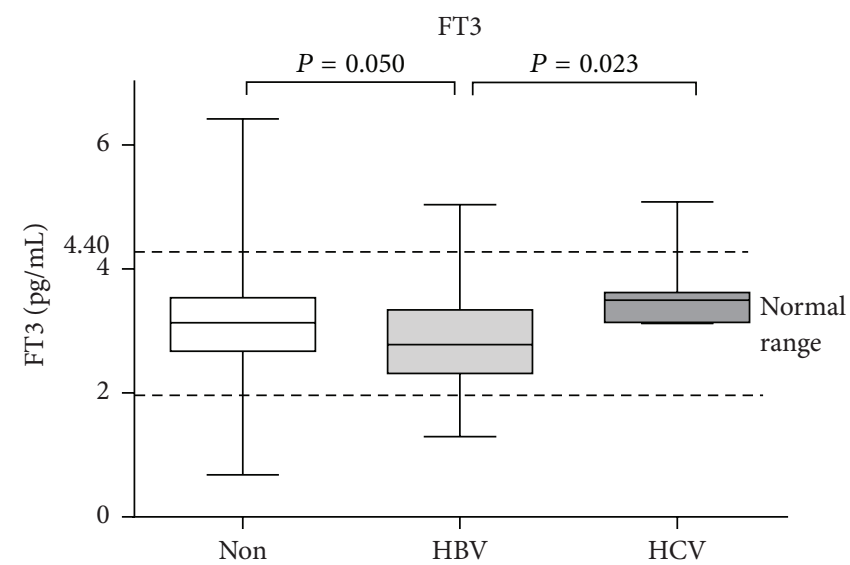

(b)

FT4

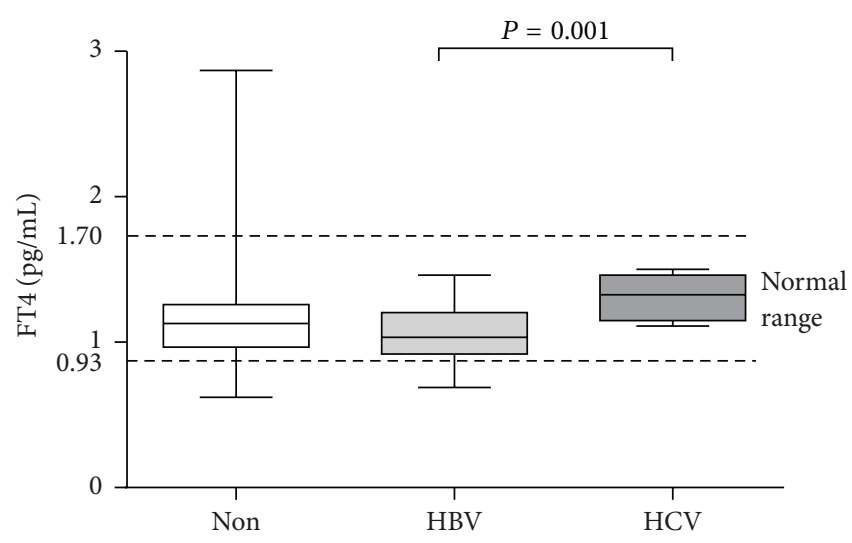

(c)

FIgURE 4: Thyroid hormone levels in HIV-infected patients with or without HBV/HCV coinfection. FT3, free tri-iodothyronine; FT4, free thyroxine; TSH, thyrotropin; HBV, hepatitis B virus (HBV) coinfection; HCV, hepatitis C virus (HCV) coinfection; Non: no HBV/HCV coinfection. Thyroid hormone of the first line of the picture belongs to all of the patients; thyroid hormone of the second line belongs to patients with normal thyroid function; thyroid hormone of the third line belongs to patients with thyroid dysfunction. The horizontal lines represent mean values, the boxes represent standard deviations, and the whiskers represent ranges. The dashed lines represent the normal ranges of thyroid hormones. $P$ values $>0.05$ in pairwise comparisons are not shown in the figure.

hypothyroidism [22]. In addition, Madeddu et al. [2] found no significant difference in the levels of FT3, FT4, and TSH between patients treated with PIs and those treated with non-PI drugs, but they observed that FT4 levels were lower in both these groups than in HAART-naïve patients, which is consistent with our findings. The role of HAART in thyroid function abnormalities development should be better clarified in a long follow-up prospective study.

FT3 and FT4 levels have been reported to be related to the state of HIV infection and are potential biomarkers of HIV progression. Beltran et al. reported that compared with HIV-infected patients with normal thyroid function, patients with hypothyroidism were older, had HIV infection for a longer duration, had lower CD4 cell counts, and were more likely to have HCV coinfection and have been treated with HAART [22]. On multivariate analysis, however, the same authors found that only stavudine treatment and low CD4 cell count were statistically associated with hypothyroidism [22]. Madeddu et al. found that TSH levels were negatively correlated with CD4 cell count nadir and positively correlated with HAART duration [2]. Our results demonstrated that FT3 and FT4 levels were negatively correlated with the duration of HIV infection and positively correlated with the CD4 cell count. We also found higher FT3 level in patients of CDC class 1 than in patients of CDC class 3. But no relevance was found between TSH level and any of above disease parameters. In our study, CD4 cell count was lower in patients with overt hypothyroidism than in those without overt hypothyroidism, indicating that FT3 and FT4 levels were related to the progression of HIV infection to some degree. However, both univariate and multivariate logistic regression models indicated that although duration of HIV infection and CD4 cell count nadir were related to thyroid dysfunction, they were not risk factors of thyroid dysfunction. Females were at higher risk to suffer from thyroid dysfunction, which was in accordance with a recent study conducted by Sharma et al. [36]. Further studies with larger samples are needed to verify our conclusion. 
Coinfection with $\mathrm{HBV} / \mathrm{HCV}$ is an important factor influencing HIV progression and the effects of HAART on immune response, liver function, endocrine function, and so forth [1]. We therefore analyzed the effects of $\mathrm{HBV} / \mathrm{HCV}$ coinfection on thyroid function in HIV-infected patients. We found that the levels of FT3 and FT4 were significantly increased in patients with HCV coinfection and decreased in patients with $\mathrm{HBV}$ coinfection. This contradicts the result reported by Beltran et al. that HCV coinfection in HIV patients is a risk factor for hypothyroidism [22]. The mechanism, via which $\mathrm{HBV} / \mathrm{HCV}$ coinfection influences thyroid function, remains unclear. $\mathrm{HBV} / \mathrm{HCV}$-related autoimmune disease or side effects of interferon treatment may be potential explanations. However, only eight patients were coinfected with $\mathrm{HCV}$ in our study, and further studies with more HIV patients coinfected with $\mathrm{HBV} / \mathrm{HCV}$ are necessary.

It is still unclear whether the cause of thyroid dysfunction in HIV patients is the HIV infection itself, its complications, therapy, or progression $[2,37,38]$. As thyroid dysfunction in HIV has been reported before the introduction of HAART, some authors have suggested that the thyroid changes are a result of opportunistic infections, regional tumors, serious systemic disease, or energy deprivation [2, 22, 39-42]. The decreased secretion of thyroid hormones may act as a form of self-protection because it decreases energy expenditure $[14,43]$. However, Bongiovanni et al. concluded that therapy had an acute influence on thyroid function because patients who had recently started HAART showed a higher incidence of subclinical hypothyroidism than those who had been on HAART for at least 1 year $[1,14,20]$. Furthermore, Silva et al. suggested that immune reconstitution was more likely to protect thyroid function than impair it, and specific antiviral agents or disease activities, rather than immunity, mediated thyroid dysfunction in most AIDS patients [14].

Although the mechanism of thyroid dysfunction in HIVinfected patients is unclear, our study indicated that HIVinfected patients, particularly those on HAART, have a high incidence of thyroid dysfunction. The most common thyroid dysfunction among HIV-infected patients was hypothyroidism. Our research showed that FT3 and FT4 levels were negatively correlated with the duration of HIV infection and positively correlated with CD4 cell count in HIV-infected patients. Both these findings indicate that FT3 and FT4 levels tend to decrease with the progression of HIV infection. Therefore, physicians should pay more attention to the detection of thyroid dysfunction in HIV-infected patients and provide timely treatment. Although there were no correlations between thyroid hormone levels and duration of HAART, we demonstrated that HAART was an important factor affecting the incidence of thyroid dysfunction. Simultaneously, the influence of drugs on thyroid function should be taken into account when starting a HAART regimen or treating $\mathrm{HBV} /$ HCV coinfection.

Our results should be interpreted within the study's limitations: first, the sample was insufficient, especially, the number of patients with HCV coinfection. Second, drug resistance was inevitable as a result of the patients' long course of infection. The patients' medication histories were complicated as indispensable drug adjustments were performed on account of realistic clinical treatment requirements, which added to the difficulty in determining the exact influence of the drugs. Finally, this research was a retrospective cross-sectional study without follow-up to identify dynamic changes in the patients' thyroid function. A dynamic, prospective study may further clarify the relationship between HIV infection, HAART, coinfection, and thyroid function.

\section{Competing Interests}

The authors declare that there are no conflict of interests.

\section{Authors' Contributions}

Shujing Ji and Changzhong Jin contributed equally to this paper.

\section{Acknowledgments}

This work was supported by the Zhejiang Provincial Science \& Technology Foundation (2015C33183), the National Key Technologies R\&D Program for the 12th Five-Year Plan of China (no. 2012ZX10001-004-005), and National Natural Science Foundation of China (81402726).

\section{References}

[1] M. Bongiovanni, F. Adorni, M. Casana et al., "Subclinical hypothyroidism in HIV-infected subjects," The Journal of Antimicrobial Chemotherapy, vol. 58, no. 5, pp. 1086-1089, 2006.

[2] G. Madeddu, A. Spanu, F. Chessa et al., "Thyroid function in human immunodeficiency virus patients treated with highly active antiretroviral therapy (HAART): a longitudinal study," Clinical Endocrinology, vol. 64, no. 4, pp. 375-383, 2006.

[3] L. C. Hofbauer and A. E. Heufelder, "Endocrine implications of human immunodeficiency virus infection," Medicine, vol. 75, no. 5, pp. 262-278, 1996.

[4] S. K. Grinspoon and J. P. Bilezikian, "HIV disease and the endocrine system," The New England Journal of Medicine, vol. 327, no. 19, pp. 1360-1365, 1992.

[5] S. K. Grinspoon, D. S. Donovan Jr., and J. P. Bilezikian, "1 Aetiology and pathogenesis of hormonal and metabolic disorders in HIV infection," Bailliere's Clinical Endocrinology and Metabolism, vol. 8, no. 4, pp. 735-755, 1994.

[6] E. Mylonakis, P. Koutkia, and S. Grinspoon, "Diagnosis and treatment of androgen deficiency in human immunodeficiency virus-infected men and women," Clinical Infectious Diseases, vol. 33, no. 6, pp. 857-864, 2001.

[7] M. Lambert, "7 Thyroid dysfunction in HIV infection," Bailliere's Clinical Endocrinology and Metabolism, vol. 8, no. 4, pp. 825-835, 1994.

[8] W. W. Tang and E. M. Kaptein, "Thyroid hormone levels in the acquired immunodeficiency syndrome (AIDS) or AIDS-related complex," The Western Journal of Medicine, vol. 151, no. 6, pp. 627-631, 1989.

[9] N. H. Brockmeyer, A. Kreuter, A. Bader, U. Seemann, and G. Reimann, "Prevalence of endocrine dysfunction in HIVinfected men," Hormone Research, vol. 54, no. 5-6, pp. 294-295, 2000.

[10] A. Carr, K. Samaras, S. Burton et al., "A syndrome of peripheral lipodystrophy, hyperlipidaemia and insulin resistance in 
patients receiving HIV protease inhibitors," AIDS, vol. 12, no. 7, pp. F51-F58, 1998.

[11] P. Rietschel, C. Corcoran, T. Stanley, N. Basgoz, A. Klibanski, and S. Grinspoon, "Prevalence of hypogonadism among men with weight loss related to human immunodeficiency virus infection who were receiving highly active antiretroviral therapy," Clinical Infectious Diseases, vol. 31, no. 5, pp. 1240-1244, 2000.

[12] M. Savès, F. Raffi, J. Capeau et al., "Factors related to lipodystrophy and metabolic alterations in patients with human immunodeficiency virus infection receiving highly active antiretroviral therapy," Clinical Infectious Diseases, vol. 34, no. 10, pp. 13961405, 2002.

[13] G. Chêne, E. Angelini, L. Cotte et al., "Role of long-term nucleoside-analogue therapy in lipodystrophy and metabolic disorders in human immunodeficiency virus-infected patients," Clinical Infectious Diseases, vol. 34, no. 5, pp. 649-657, 2002.

[14] G. A. Silva, M. C. Andrade, A. Sugui Dde et al., "Association between antiretrovirals and thyroid diseases: a cross-sectional study," Archives of Endocrinology and Metabolism, vol. 59, no. 2, pp. 116-122, 2015.

[15] C. J. Hoffmann and T. T. Brown, "Thyroid function abnormalities in HIV-infected patients," Clinical Infectious Diseases, vol. 45, no. 4, pp. 488-494, 2007.

[16] A. S. Dobs, M. A. Dempsey, P. W. Ladenson, and B. F. Polk, "Endocrine disorders in men infected with human immunodeficiency virus," The American Journal of Medicine, vol. 84, no. 3, part 2, pp. 611-616, 1988.

[17] D. E. Sellmeyer and C. Grunfeld, "Endocrine and metabolic disturbances in human immunodeficiency virus infection and the acquired immune deficiency syndrome," Endocrine Reviews, vol. 17, no. 5, pp. 518-532, 1996.

[18] M. J. T. Hommes, J. A. Romijn, M. H. Godfried et al., "Increased resting energy expenditure in human immunodeficiency virusinfected men," Metabolism: Clinical and Experimental, vol. 39, no. 11, pp. 1186-1190, 1990.

[19] M. J. T. Hommes, J. A. Romijn, E. Endert et al., "Hypothyroidlike regulation of the pituitary-thyroid axis in stable human immunodeficiency virus infection," Metabolism, vol. 42, no. 5, pp. 556-561, 1993.

[20] A. A. Parsa and A. Bhangoo, "HIV and thyroid dysfunction," Reviews in Endocrine and Metabolic Disorders, vol. 14, no. 2, pp. 127-131, 2013.

[21] A. P. Weetman, “Thyroid abnormalities," Endocrinology and Metabolism Clinics of North America, vol. 43, no. 3, pp. 781-790, 2014.

[22] S. Beltran, F.-X. Lescure, R. Desailloud et al., "Increased prevalence of hypothyroidism among human immunodeficiency virus-infected patients: a need for screening," Clinical Infectious Diseases, vol. 37, no. 4, pp. 579-583, 2003.

[23] S. Thongam, S. Keithelakpam, T. Y. Singh, R. L. Singh, A. M. Singh, and S. Ranabir, "Thyroid dysfunction in human immunodeficiency virus-infected children and its correlation with $\mathrm{CD}^{+}$T lymphocyte count," Indian Journal of Endocrinology and Metabolism, vol. 19, no. 2, pp. 272-276, 2015.

[24] L. Calza, R. Manfredi, and F. Chiodo, "Subclinical hypothyroidism in HIV-infected patients receiving highly active antiretroviral therapy," Journal of Acquired Immune Deficiency Syndromes, vol. 31, no. 3, pp. 361-363, 2002.

[25] S. Beltran, F.-X. Lescure, I. El Esper, J.-L. Schmit, and R. Desailloud, "Subclinical hypothyroidism in HIV-infected patients is not an autoimmune disease," Hormone Research, vol. 66, no. 1, pp. 21-26, 2006.

[26] F. Chiarelli, L. Galli, A. Verrotti, L. Di Ricco, A. Vierucci, and M. De Martino, "Thyroid function in children with perinatal human immunodeficiency virus type 1 infection," Thyroid, vol. 10, no. 6, pp. 499-505, 2000.

[27] M. Grappin, L. Piroth, B. Verges et al., "Increased prevalence of subclinical hypothyroidism in HIV patients treated with highly active antiretroviral therapy," AIDS, vol. 14, no. 8, pp. 1070-1072, 2000.

[28] K. Sato, T. Satoh, K. Shizume et al., "Inhibition of 125I organification and thyroid hormone release by interleukin-1, tumor necrosis factor- $\alpha$, and interferon- $\gamma$ in human thyrocytes in suspension culture," The Journal of Clinical Endocrinology and Metabolism, vol. 70, no. 6, pp. 1735-1743, 1990.

[29] I. S. Fentiman, B. S. Thomas, F. R. Balkwill, R. D. Rubens, and J. L. Hayward, "Primary hypothyroidism associated with interferon therapy of breast cancer," The Lancet, vol. 325, no. 8438, p. $1166,1985$.

[30] "1993 revised classification system for HIV infection and expanded surveillance case definition for AIDS among adolescents and adults," Morbidity and Mortality Weekly Report, vol. 41, no. 17, pp. 1-19, 1992.

[31] J. Collazos, S. Ibarra, and J. Mayo, "Thyroid hormones in HIVinfected patients in the highly active antiretroviral therapy era: evidence of an interrelation between the thyroid axis and the immune system," AIDS, vol. 17, no. 5, pp. 763-765, 2003.

[32] M. Nelson, T. Powles, A. Zeitlin et al., "Thyroid dysfunction and relationship to antiretroviral therapy in HIV-positive individuals in the HAART era," Journal of Acquired Immune Deficiency Syndromes, vol. 50, no. 1, pp. 113-114, 2009.

[33] J.-J. Wang, J.-J. Zhou, X.-L. Yuan et al., "Hyperthyroidism caused by acquired immune deficiency syndrome," European Review for Medical and Pharmacological Sciences, vol. 18, no. 6, pp. 875-879, 2014.

[34] S. Rasul, R. Delapenha, F. Farhat, J. Gajjala, and S. M. Zahra, "Graves' disease as a manifestation of immune reconstitution in HIV-infected individuals after initiation of highly active antiretroviral therapy," AIDS Research and Treatment, vol. 2011, Article ID 743597, 4 pages, 2011.

[35] M. E. Sobieszczyk, D. R. Hoover, K. Anastos et al., "Prevalence and predictors of metabolic syndrome among HIV-infected and HIV-uninfected women in the women's interagency HIV study," Journal of Acquired Immune Deficiency Syndromes, vol. 48, no. 3, pp. 272-280, 2008.

[36] N. Sharma, L. K. Sharma, D. Dutta et al., "Prevalence and predictors of thyroid dysfunction in patients with HIV infection and acquired immunodeficiency syndrome: an Indian perspective," Journal of Thyroid Research, vol. 2015, Article ID 517173, 9 pages, 2015.

[37] C. Grunfeld, M. Pang, W. Doerrler et al., "Indices of thyroid function and weight loss in human immunodeficiency virus infection and the acquired immunodeficiency syndrome," Metabolism: Clinical and Experimental, vol. 42, no. 10, pp. 12701276, 1993.

[38] W. Ricarf-Engel, J. M. Fernández-Real, F. González-Huix, M. Del Pozo, J. Mascaró, and F. García-Bragado, "The relation between thyroid function and nutritional status in HIV-infected patients," Clinical Endocrinology, vol. 44, no. 1, pp. 53-58, 1996.

[39] K. Welch, W. Finkbeiner, C. E. Alpers et al., "Autopsy findings in the acquired immune deficiency syndrome," The Journal of 
the American Medical Association, vol. 252, no. 9, pp. 1152-1159, 1984.

[40] R. Battan, P. Mariuz, M. C. Raviglione, M. T. Sabatini, M. P. Mullen, and L. Poretsky, "Pneumocystis carinii infection of the thyroid in a hypothyroid patient with AIDS: diagnosis by fine needle aspiration biopsy," The Journal of Clinical Endocrinology and Metabolism, vol. 72, no. 3, pp. 724-726, 1991.

[41] D. J. Drucker, D. Bailey, and L. Rotstein, "Thyroiditis as the presenting manifestation of disseminated extrapulmonary Pneumocystis carinii infection," The Journal of Clinical Endocrinology and Metabolism, vol. 71, no. 6, pp. 1663-1665, 1990.

[42] L. C. Mollison, A. Mijch, G. McBride, and B. Dwyer, "Hypothyroidism due to destruction of the thyroid by Kaposi's sarcoma," Reviews of Infectious Diseases, vol. 13, no. 5, pp. 826-827, 1991.

[43] T. T. Brown, "The effects of HIV-1 infection on endocrine organs," Best Practice and Research: Clinical Endocrinology and Metabolism, vol. 25, no. 3, pp. 403-413, 2011. 


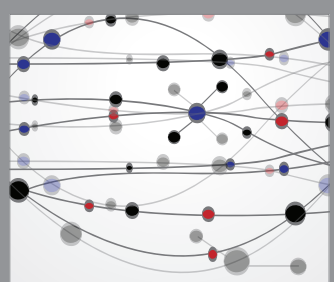

The Scientific World Journal
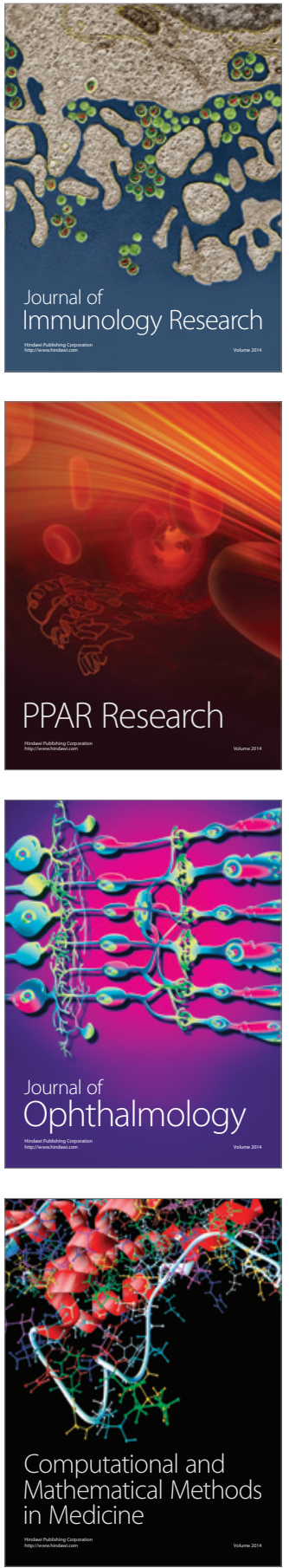

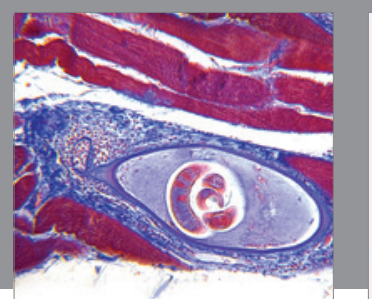

Gastroenterology Research and Practice

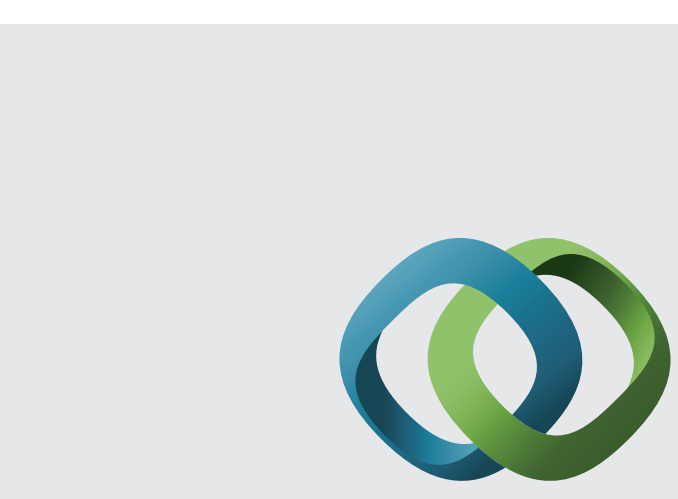

\section{Hindawi}

Submit your manuscripts at

http://www.hindawi.com
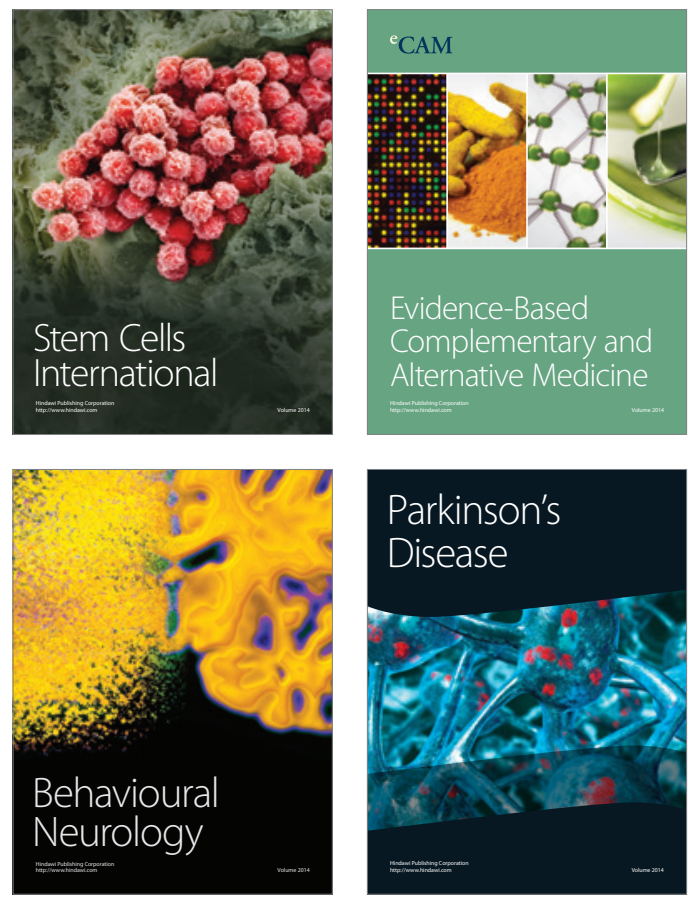
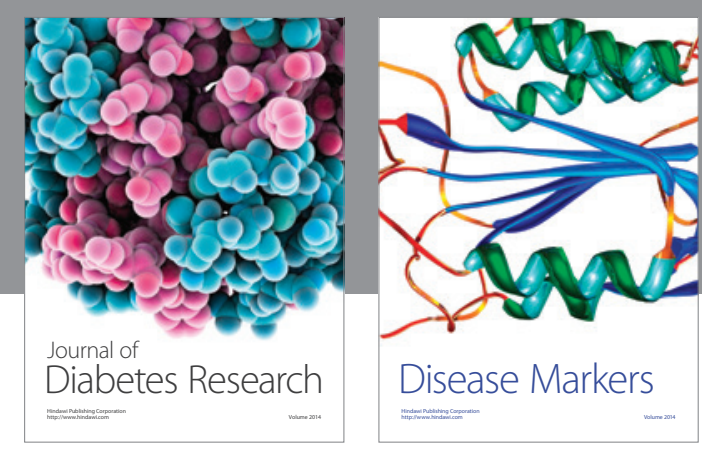

Disease Markers
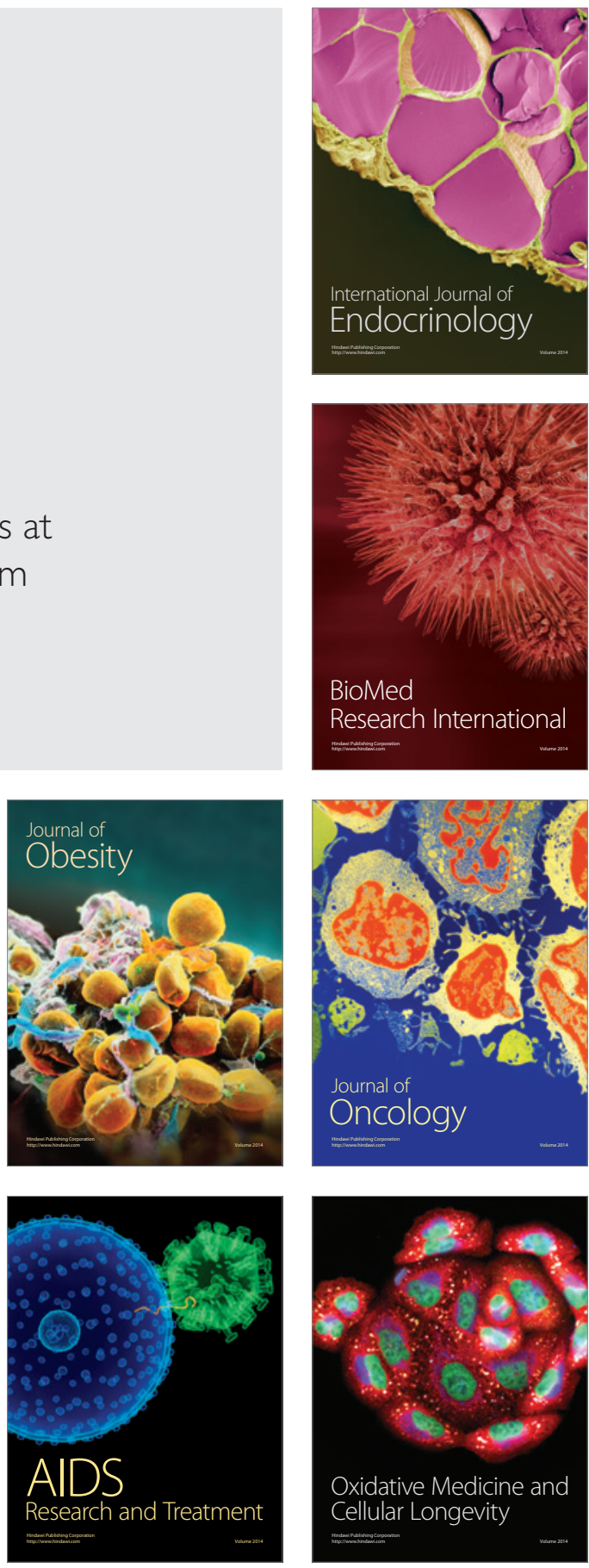